\title{
Anti-tumor activity of an immunotoxin (TGFa-PE38) delivered by attenuated Salmonella typhimurium
}

\author{
Daejin Lim ${ }^{1,2}$, Kwang Soo Kim ${ }^{1,2}$, Hyun-Ju Kim ${ }^{1,2}$, Kyong-Cheol Ko ${ }^{4}$, Jae Jun Song ${ }^{4}$, \\ Jong Hyun Choi ${ }^{4}$, Minsang Shin ${ }^{5}$, Jung-Joon Min ${ }^{2,3}$, Jae-Ho Jeong ${ }^{1,2}$, Hyon E. Choy ${ }^{1,2}$ \\ ${ }^{1}$ Department of Microbiology, Chonnam National University Medical School, Gwangju, Republic of Korea \\ ${ }^{2}$ Molecular Medicine, BK21 Plus, Chonnam National University Graduate School, Gwangju, Republic of Korea \\ ${ }^{3}$ Department of Nuclear Medicine, Chonnam National University Medical School, Gwangju, Republic of Korea \\ ${ }^{4}$ Applied Microbiology Research Center, Bio-Materials Research Institute, Korea Research Institute of Bioscience and \\ Biotechnology, Jeongeup, Jeonbuk, Republic of Korea \\ ${ }^{5}$ Department of Microbiology, Kyungpook National University Medical School, Daegu, Republic of Korea \\ Correspondence to: Hyon E. Choy, email: hyonchoy@jnu.ac.kr \\ Jung-joon Min, email: jjmin@jnu.ac.kr \\ Jae-Ho Jeong, email: wogh96@hanmail.net
}

Keywords: immunotoxin, TGFa-PE38, bacterial cancer therapy, Salmonella

Received: September 20, 2016

Accepted: April 06, 2017

Published: April 18, 2017

Copyright: Lim et al. This is an open-access article distributed under the terms of the Creative Commons Attribution License (CC-BY), which permits unrestricted use, distribution, and reproduction in any medium, provided the original author and source are credited.

\section{ABSTRACT}

The anticancer strategy underlying the use of immunotoxins is as follows: the cancer-binding domain delivers the toxin to a cancer cell, after which the toxin enters and kills the cell. TGFa-PE38 is an immunotoxin comprising transforming growth factor alpha (TGFa), a natural ligand of epidermal growth factor receptor (EGFR), and a modified Pseudomonas exotoxin A (PE38) lacking $\mathbf{N}$ terminal cell-binding domain, a highly potent cytotoxic protein moiety. Tumor cells with high level of EGFR undergo apoptosis upon treatment with TGFa-PE38. However, clinical trials demonstrated that this immunotoxin delivered by an intracerebral infusion technique has only a limited inhibitory effect on intracranial tumors mainly due to inconsistent drug delivery. To circumvent this problem, we turned to tumor-seeking bacterial system. Here, we engineered Salmonella typhimurium to selectively express and release TGFa-PE38. Engineered bacteria were administered to mice implanted with mouse colon or breast tumor cells expressing high level of EGFR. We observed that controlled expression and release of TGFa-PE38 from intra-tumoral Salmonellae by either an engineered phage lysis system or by a bacterial membrane transport signal led to significant inhibition of solid tumor growth. These results demonstrated that delivery by tumor-seeking bacteria would greatly augment efficacy of immunotoxin in cancer therapeutics.

\section{INTRODUCTION}

Several recombinant immunotoxins developed to target malignant tumors are now undergoing clinical trials $[1,2]$. Immunotoxins comprise a cancer-binding moiety linked to a potent toxin lacking an intrinsic cell-binding domain. The cancer-binding moiety most often comprises part of a monoclonal antibody, although cytokines or growth factors that interact with receptors highly expressed by cancer cells have also been used. The idea behind anticancer strategies based on immunotoxins is that the cancer-binding moiety brings the toxin to cancer cells; the toxin then enters and kills the cells. Many tumor cells express high levels of epidermal growth factor receptor (EGFR) [3]. Transforming growth factor alpha (TGF $\alpha$ ) is a natural ligand for the EGFR, which plays a central role in cancer development. A recombinant immunotoxin comprising TGF $\alpha$ and a modified Pseudomonas exotoxin A (PE38) derived from Pseudomonas aeruginosa was developed for treatment of EGFR-expressing malignant tumors, e.g. brain tumors $[4,5]$. Pseudomonas exotoxin A acts by inactivating protein synthesis in mammalian cells [6]. PE38, which lacks an intrinsic cell-binding domain, binds to EGFR-expressing cancer cells via the $\mathrm{TGF} \alpha$ moiety within the recombinant toxin. It has been demonstrated that the TGF $\alpha$-PE38 fusion protein was 
cytotoxic to EGFR-expressing tumor cells in vitro and in xenograft mouse models $[1,7]$. However, there are some limitations. For example, dose-limiting hepatotoxicity was noted when high levels of TGF $\alpha$-PE38 were administered systemically [7]. It was suggested that a direct intratumoral drug delivery could ensure successful application of TGF $\alpha$-PE38 for the treatment of solid tumors, including intracranial glioblastoma. Thus, TGF $\alpha$-PE38 was delivered directly to the tumor to treat intracranial implants of glioblastoma cells in nude mice. Intra-tumoral delivery was imperative to avoid the hepatotoxicity but also to solve a problem of its short half-live (the analogous construct TGFa-PE40 has a half-life of 10-20 min [8]). In a subsequent clinical trial of human patients with recurrent malignant brain tumors, TGF $\alpha$-PE38 was delivered by an intracerebral infusion technique [9]. However, a limited positive response was observed, mainly due to inconsistent drug delivery by this technique.

Bacterial strains from several phylogenetic groups, including Salmonella, Clostridium, Bifidobacterium, Listeria, Vibrio, and Escherichia coli (E. coli), selectively target and proliferate within solid tumors in mouse models [10-15]; indeed, bacterial anticancer therapy was developed to take advantage of these properties. Recently, bacterial anticancer therapy using a mutant Salmonella typhimurium was clinically tested in canines and in human patients [16-18]. As cancer therapeutic agents, bacteria possess several advantages [19-22]. First, these bacteria preferentially overgrow within tumors, resulting in $\sim 1,000$-fold (or even higher) increase in bacterial numbers in tumor tissues relative to normal organs such as the liver and spleen. Second, they can actively swim away from the vasculature and penetrate deep into tumor tissue, keeping high concentration in hypoxic tumor tissue. Third, native bacterial cytotoxicity can suppress tumor growth. Fourth, the oncolytic effect of bacteria is significantly enhanced if tumor-targeting bacteria are armed with cytolytic proteins such as bacterial cytolysin (CytA). Recently, R. Hoffman's group, which has been used a modified auxotrophic strain of Salmonella typhimurium A1R rather successfully by itself to eradicate metastatic as well as primary tumors [14, 23-30], also began combinatorial approach with chemotherapy after finding that A1R strain decoyed chemo-resistant quiescent cancer cells in tumors to cycle from $\mathrm{G} 0 / \mathrm{G} 1$ to $\mathrm{S} / \mathrm{G} 2 / \mathrm{M}$, thereby rendering these cells sensitive to cytotoxic agents: a new paradigm of "decoy, trap and shoot" chemotherapy [28-30].

Here, we have used $\Delta \mathrm{ppGpp}$ mutant Salmonellae armed with recombinant TGF $\alpha-\mathrm{PE} 38$ to treat solid tumors. This strain of bacteria is incapable of invading or proliferating in animal cell $[31,32]$ but it alone has been shown to be anti-tumoral, although temporal, by inducing expression of pro-inflammatory cytokines, interleukin- $1 \beta$ and tumor necrosis factor $\alpha$, expressed by intra-tumoral macrophages and neutrophils [33]. In this study, we constructed a plasmid harboring TGF $\alpha$-PE38, which was then expressed in this Salmonellae targeted to tumors implanted in mice using an induction system based on the $P_{\mathrm{BAD}}$ promoter from E. coli; this promoter is inducible by intraperitoneal (i.p.) injection of L-arabinose [20]. TGF $\alpha$-PE38 was exported out of Salmonellae either by an engineered phage lysis system [34] or by a bacterial membrane transport signal fused to the protein. The results of the animal studies showed that controlled expression and release of TGF $\alpha$-PE38 from Salmonella resulted in significant retardation of tumor growth better than the Salmonella alone.

\section{RESULTS}

\section{Construction and analysis of plasmids expressing TGF $\alpha$-PE38, SEC-TGF $\alpha$-PE38, and PE38}

In bacterial anticancer therapy, it is essential to maintain the plasmid carrying the gene encoding the oncolytic protein in the absence of selection pressure (e.g., via antibiotics) in animals. The plasmid should therefore be equipped with a balanced-lethal host vector system [35]. The current study used a system based on the $g \operatorname{lm} S$ gene, which is essential for peptidoglycan synthesis in Salmonella [36]. Mutants defective in $g \operatorname{lm} S$ are strictly dependent on the presence of exogenous D-glucosamine $(\mathrm{GlcN})$ and N-acetyl-D-glucosamine (GlcNAc). Since these compounds are not present in mammalian tissues, this balanced-lethal system requires that Salmonellae carry the recombinant $\mathrm{GlmS}^{+}$plasmid to survive. In addition, recombinant oncolytic proteins expressed in bacteria must be exported out of bacteria to be effective against tumors. Previously, we reported that induction of a plasmid ( $p L Y S$ ) carrying a Salmonellae lysis system consisting of three genes from a Salmonella bacteriophage (iEPS5) effectively lysed bacteria and released their contents [34]. On this plasmid background ( $p L Y S$ ), a DNA fragment containing the open reading frame of TGF $\alpha$ PE38 or PE38 was cloned under control of the inducible araBAD promoter of $E$. coli to generate $p T G F \alpha-P E 38$ or $p P E 38$ (Figure 1A). Alternatively, we intended to take an advantage of bacterial signal peptide to export TGF $\alpha$-PE38 out of Salmonella cells [37]. To identify the optimal signal peptide for export of TGF $\alpha$-PE38, we tested various signal peptides, including the pelB leader sequence of the gene for pectatelyase B from Erwiniacarotovora [38], CelExBR12 [39], and a new cellulase (Psp) from Paenibacillus sp. EC003, which was isolated from soil as a cellulolytic microorganism that formed a clear zone on LB agar plates containing Azo-CM-cellulose (manuscript in preparation). The Psp signal peptide comprised of 32 amino acids (MGLKMKKRSGKKAWMLLVMSLLIAAVPITASA) allowed efficient export of TGF $\alpha$-PE38 (see below). A plasmid carrying the Psp secretion signal, fused in-frame to the $\mathrm{N}^{\prime}$ end of TGF $\alpha$-PE38 was constructed in the same way, on the $p L Y S$ plasmid background lacking the phage 
lysis system; this plasmid was named pSEC-TGF $\alpha$-PE38. TGF $\alpha$-PE38 fused to this signal peptide should be secreted out of bacteria upon induction by L-arabinose. $\Delta \mathrm{ppGpp}$ S. typhimurium was used, since it is highly attenuated in mouse models $[32,40]$.

Using Salmonellae carrying the above plasmid constructs, we then examined the controlled induction of TGF $\alpha-P E 38$ and/or bacterial lysis in vitro. $\Delta$ ppGpp Salmonella carrying these constructs were grown in LB medium. Two hours after inoculation, when the $\mathrm{A}_{600}$ of the culture had reached to approximately 1.0, L-arabinose was added (final concentration, $0.2 \%$ ) and the bacteria were grown for additional 1 hour. The cultures were harvested, divided into supernatant and pellet fractions after centrifugation, and analyzed for the presence of TGF $\alpha$ PE38 or PE38 by Western blotting with a polyclonal antibody against Pseudomonas exotoxin A (Figure 1B). Salmonellae carrying $p S E C-T G F a-P E 38$ were analyzed in the same manner to examine release of TGF $\alpha-P E 38$ through the Psp secretion signal peptide. In harvested whole cell cultures, the antibody detected TGF $\alpha$-PE38 or PE38 protein only after addition of L-arabinose, demonstrating tight control by the araBAD promoter. Examination of the supernatant and pellet fractions after induction of the phage lysis system revealed that most of the target protein was present in the supernatant, demonstrating that the phage lysis system is effective. Note that SEC-TGF $\alpha$-PE38 was detected in two forms, with and without a SEC signal peptide, in whole cell culture samples. However, only mature product lacking the signal peptide was observed in the supernatant fraction, while both forms were detected in the pellet fraction. The Psp signal peptide (MW 3.44 KDa) is cleaved upon translocation of the cargo protein out of the bacterial cell membrane. Taken together, these results show that engineered Salmonellae express and release TGF $\alpha$-PE38 effectively in the presence of L-arabinose.

\section{Effect of TGF $\alpha$-PE38 expressed by Salmonella typhimurium on cultured cancer cells}

TGF $\alpha$-PE38 should be effective against EGFRexpressing cancer cells [41]. The effect was examined using two mouse colon cancer cell lines, CT26 and MC38, a mouse breast cancer cell line, 4T1, expressing considerable levels of EGFR [42, 43], and human colon cancer cells, SW620, expressing little EGFR [44]. Subsequently, TGF $\alpha$-PE38/PE38 expressed and released from Salmonella into the culture medium was filtered through $0.45 \mu \mathrm{m}$ pore filter, concentrated to $100 \mu \mathrm{g} /$ $\mathrm{ml}$, and tested on the above cultured tumor cells. After 24 hours of treatment, the cytotoxic effect of TGF $\alpha$-PE38 was examined in an MTT assay (Figure 2). TGF $\alpha$-PE38 in the filtrate was highly, although variably, cytotoxic to all tumor cell lines tested, with the exception of SW620 cells. Also, the effect was about the same irrespective

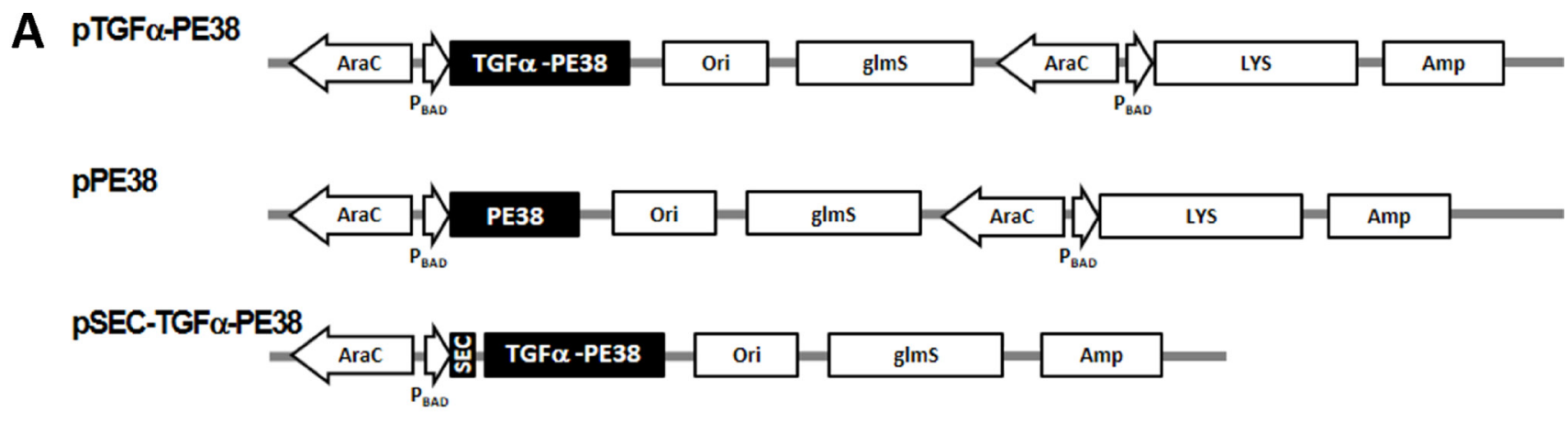

B
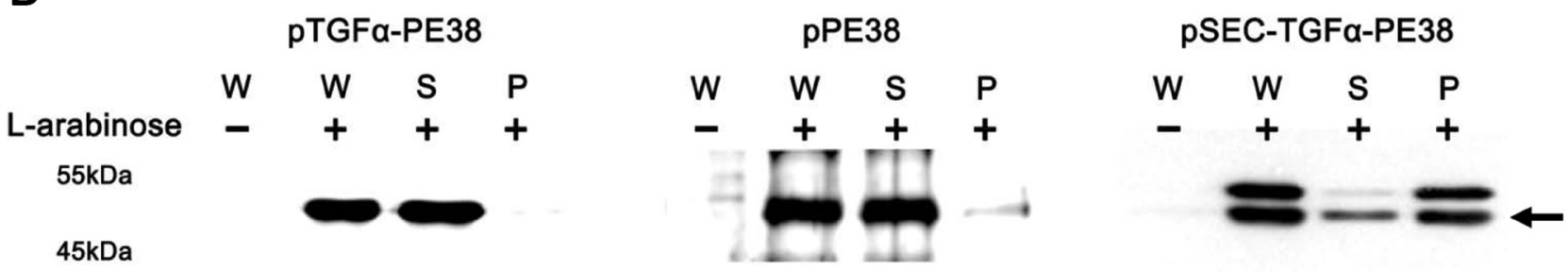

Figure 1: (A) Map of the plasmids used in this study: $p T G F \alpha-P E 38$ carries the $8293 \mathrm{bp} T G F \alpha$-PE38 DNA fragment under control of the $\mathrm{P}_{\mathrm{BAD}}$ promoter on a $p L Y S$ background [34]; $P P E 38$ is the same as above, but lacks TGF $\mathrm{DNA}$; $p S E C-T G F a-P E 38$ is the same as $p T G F \alpha-$ $P E 38$ but carries a secretion sequence before the $T G F \alpha$ DNA and lacks LYS (a phage lysis gene). (B) $\triangle$ ppGpp $S$. typhimurium carrying one of these plasmids was grown overnight in LB medium, diluted 50-fold in the same medium, and grown for 2 hours. L-arabinose was added at a final concentration of $0.2 \%$. Samples were taken after 1 hour, and expression and release of cargo protein from the Salmonellae carrying the above plasmids were examined. The bacterial culture $(\mathrm{W})$ was split into supernatant $(\mathrm{S})$ and pellet $(\mathrm{P})$ fractions by centrifugation $(3,000 \times \mathrm{g} / 15 \mathrm{~min})$. TGF $\alpha$-PE38/PE38 was examined by Western blot analysis using antibody specific for Pseudomonas exotoxin A. Arrow indicates mature product. 
of the source (phage lysis system or the signal peptide). PE38 lacking the cancer cell-binding moiety showed little cytotoxic effect. As a control, filtered media from induced cultures of the same Salmonella carrying the parental plasmid, $p L Y S$ were tested and found to be marginally toxic presumably owing to a contamination of bacterial endotoxin released upon bacterial lysis. Thus, we concluded that the cytotoxic effect conferred by TGF $\alpha$ PE38 was mainly resulted from the cooperative effect of the EGFR-binding moiety and the toxin moiety of TGF $\alpha$ PE38.

\section{Effect of TGF $\alpha$-PE38 expressed by Salmonellae in mouse tumor models}

The anti-tumor effects of TGF $\alpha$-PE38 expressed and released from intra-tumoral Salmonella were determined in
BALB/c mice bearing CT26 colon cancer cell xenografts. When the tumors reached to approximately $150 \mathrm{~mm}^{3}$ [20], $\triangle$ ppGpp Salmonella $\left(5 \times 10^{7}\right.$ Colony Forming Unit, CFU $)$ carrying either $p T G F a-P E 38$ or $p S E C-T G F \alpha-P E 38$ were injected through the tail vein. Three days post-injection (dpi), when the bacterial number in the tumor is highest [46], L-arabinose (120 mg) was administered into the peritoneal cavity. After 24 hours (i.e., $4 d p i$ ), the mice were sacrificed, tumor tissues were excised, bacterial numbers were counted, and TGF $\alpha-\mathrm{PE} 38$ expression was examined by Western blotting with a specific antibody. A second round of the induction was carried out by administering L-arabinose at $7 d p i$ and examining tumor tissues at $8 d p i$ (Figure 3A). The number of Salmonella carrying $p T G F a-$ $P E 38$, and thus equipped with the phage lysis system, in L-arabinose-treated tumors was $\sim 10^{6} \mathrm{CFU} / \mathrm{g}$ tissue $\left(\mathrm{CFU} \mathrm{g}^{-1}\right)$ at $4 d p i$, while that in untreated tumors was $\sim 10^{9}$
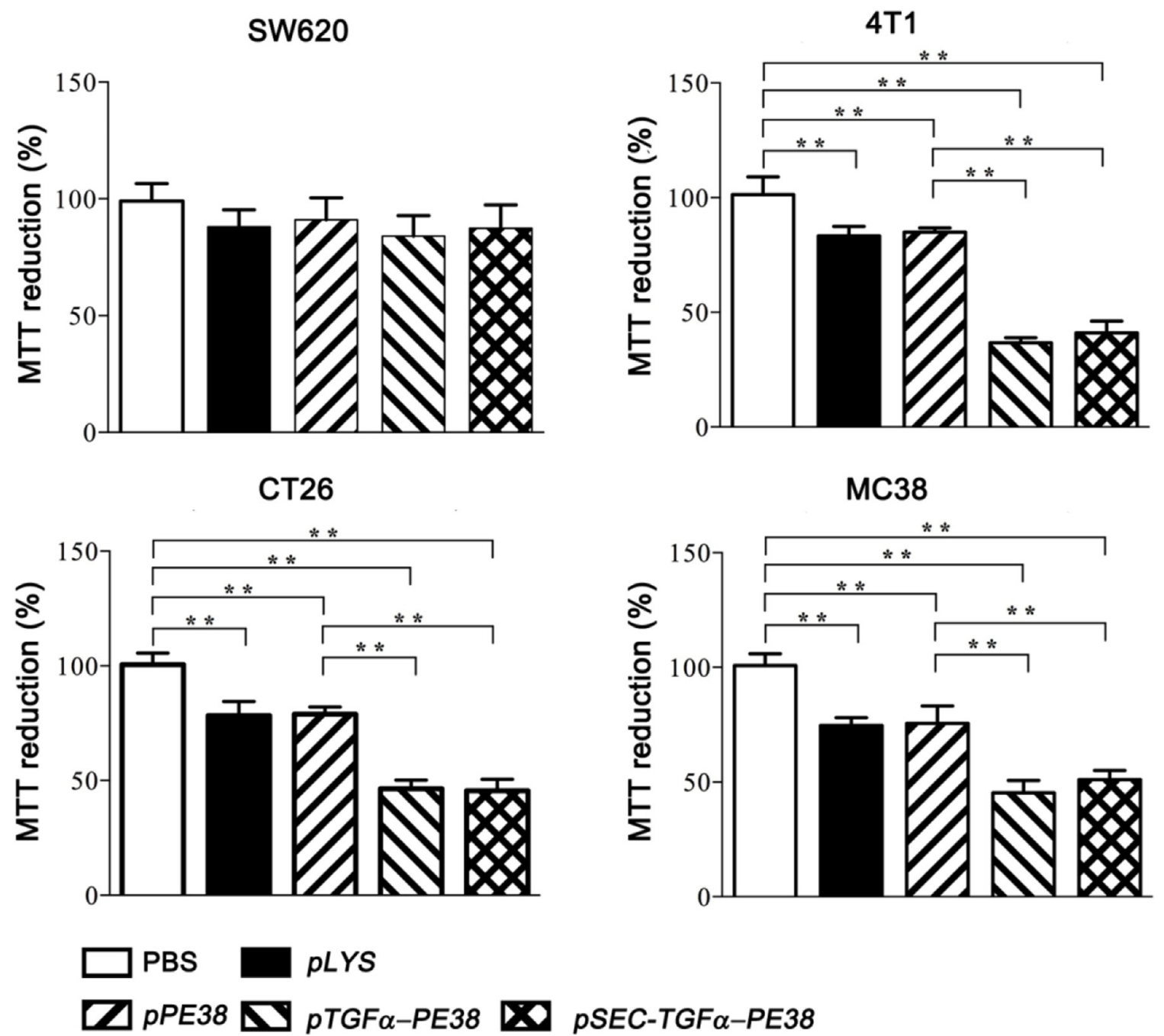

Figure 2: Fate of cancer cells treated for 24 hours with supernatant from a Salmonella culture containing TGF $\alpha$-PE38 (released by the phage lysis system or by the secretory signal peptide) or PE38. Bacterial culture supernatant from Salmonella carrying the vector plasmid expressing the phage lysis system $(p L Y S)$ was also included in addition to PBS control. Cell death was assessed in a MTT assay. The degree of cell death was expressed relative to PBS-treated control $(100 \%)$. Data are expressed as the mean \pm SD $(n=4)$, and asterisks $(*)$ indicate a significant difference compared with untreated controls $(* P<0.05)$. 
$\mathrm{CFU} \mathrm{g}^{-1}$. The number of intra-tumoral Salmonella at $8 \mathrm{dpi}$ (induced once at 3 and again at $7 \mathrm{dpi}$ ) was $\sim 10^{4} \mathrm{CFU} \mathrm{g}^{-1}$, while that induced once (at $3 \mathrm{dpi}$ ) was $\sim 10^{6} \mathrm{CFU} \mathrm{\textrm {g } ^ { - 1 }}$. These results suggested that the phage lysis system induced by L-arabinose resulted in $>99.9 \%$ bacterial lysis each time, consistent with our previous observations [34]. We also examined the expression and release of TGF $\alpha$-PE38 by intra-tumoral Salmonellae (Figure 3B). Tumor tissues were homogenized and passed through a $0.45 \mu \mathrm{m}$ pore filter to remove unlysed bacteria, and the filtrate and remaining cell pellet were separated and analyzed for TGF $\alpha-P E 38$ by Western blotting. TGF $\alpha$-PE38 was detected only in L-arabinose-treated mice (Figure 3B, whole cells). A significant level of TGF $\alpha$-PE38 was detected in the filtrate from tissue samples, indicating that this protein was released from intra-tumoral Salmonellae. The level of TGF $\alpha$-PE38 after the second round of induction was considerably less than that after the first round, reflecting the reduction in bacterial numbers. The same experiment was carried out with Salmonella harboring $p S E C-T G F \alpha-P E 38$. In this case, the number of bacteria after two rounds of induction was hardly reduced (Figure 3C). When we analyzed expression of TGF $\alpha$-PE38, we detected similar levels after the first and second inductions. It was also noted that released TGF $\alpha$ PE38 lacking the signal peptide prevailed in the filtrate, while both forms of TGF $\alpha$-PE38 were detected in the pellet. Thus, the Psp secretion signal works in the mouse model as well as in vitro. These results confirmed that Salmonellae carrying either $p T G F \alpha-P E 38$ or $p S E C-T G F a-P E 38$ targeted grafted tumor tissue, where they expressed and released TGF $\alpha$-PE38 specifically upon the administration of L-arabinose.

Finally, we examined the anti-tumor activity of the engineered Salmonella in vivo. BALB/c mice were grafted with CT26 and 4T1 tumors, C57BL/6 mice with MC38 tumors, and nude mice with SW620. Tumorbearing mice were then intravenous-injected with PBS,
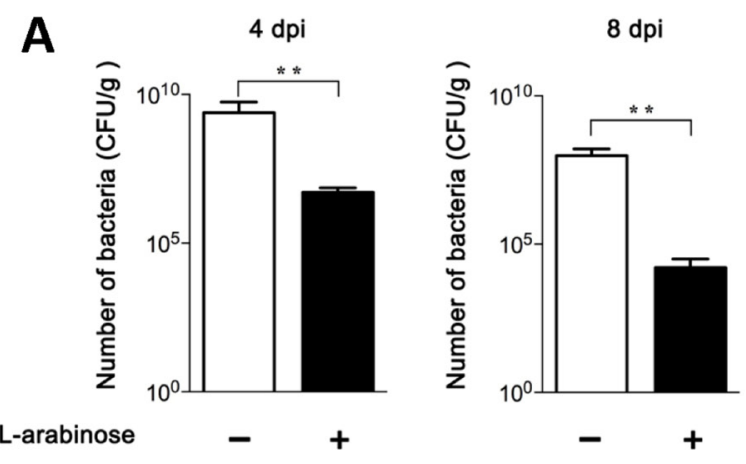

B

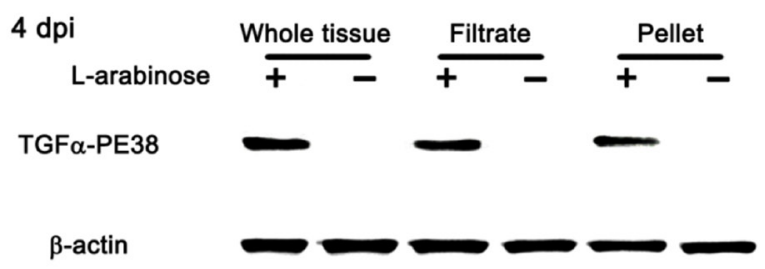

C
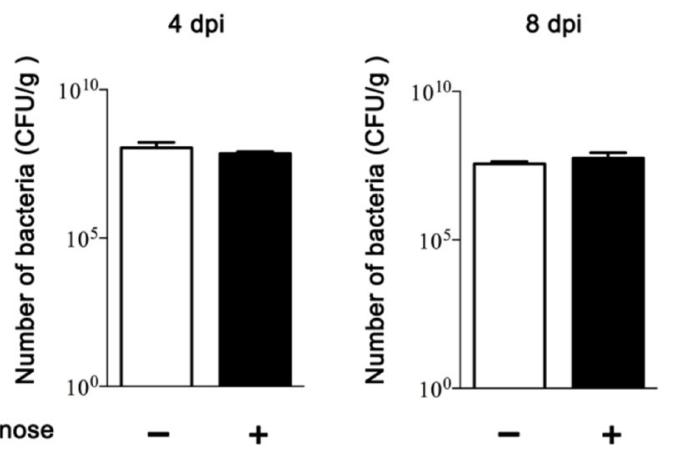

D
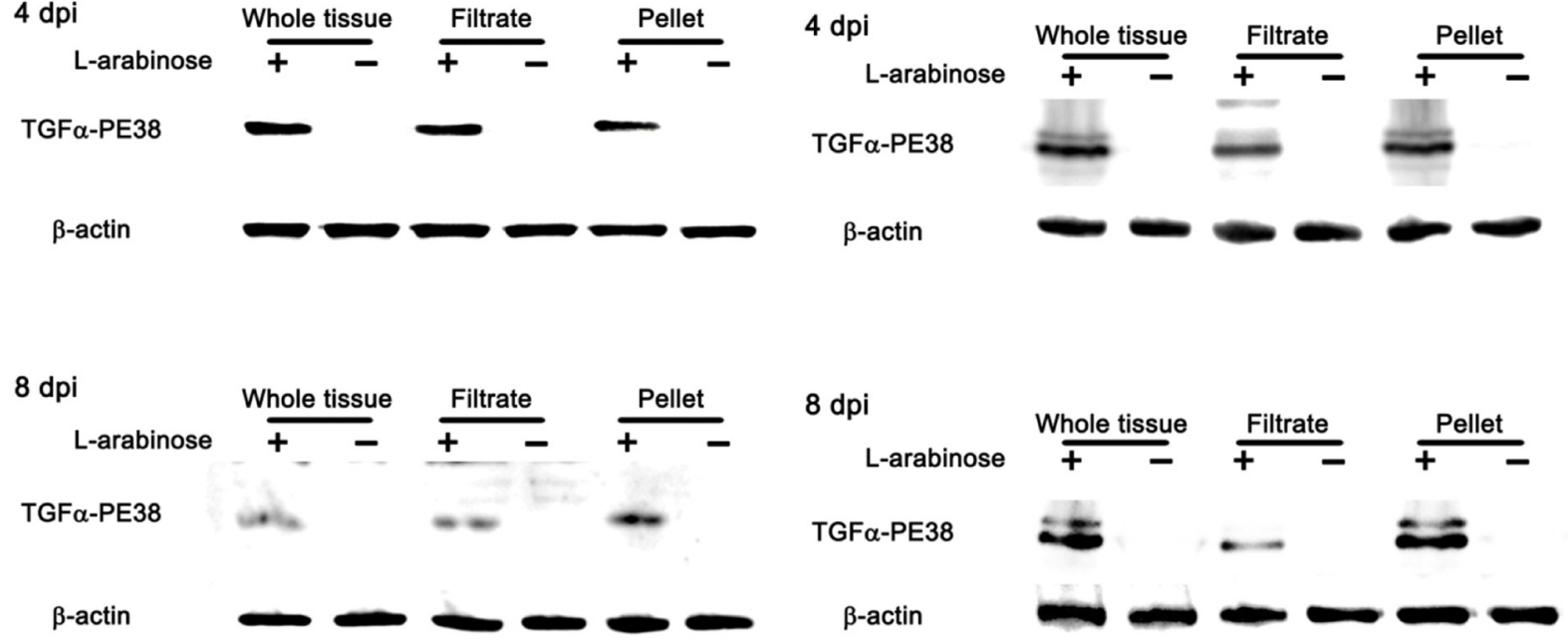

Figure 3: Expression and release of TGF $\alpha$-PE38 from intra-tumoral Salmonellae. (A and B) Salmonellae carrying $p T G F \alpha$ PE38 was injected into BALB/c mice implanted with CT26 cells via the tail vein. L-arabinose was administered into the peritoneal cavity at 3 and 7 days post-injection (dpi), and the number of Salmonella was determined at 4 and 8 dpi. Filled bars indicate L-arabinose treatment; open bars indicate no L-arabinose treatment (A). (B) Expression and release of TGF $\alpha-P E 38$ from intra-tumoral Salmonellae was determined 1 day after induction by L-arabinose administration(4 and $8 \mathrm{dpi}$ ). Whole tumor tissues were excised and separated into filtrate and pellet fractions. TGF $\alpha$-PE38 was determined by Western blotting with a specific antibody. Panels (C) and (D) show result of treatment with Salmonellae carrying $p S E C-T G F \alpha-P E 38$. Total number of Salmonellae (C) and the expression and release of $S E C-T G F \alpha-P E 38$ (D) were determined at indicated days. 
or $5 \times 10^{7}$ CFU Salmonella alone or Salmonella carrying $p T G F \alpha-P E 38$ with or without L-arabinose administration or with Salmonella carrying SEC-TGF $-P E 38$ with or without L-arabinose administration. Tumor growth was then measured every 2 days (Figure 4A). Representative gross morphological changes of tumors are shown in Supplementary Figure 1. Treatment of tumor-bearing mice with Salmonellae carrying $p T G F \alpha-P E 38$ or $p S E C$ $T G F \alpha-P E 38$, followed by induction with L-arabinose (at $3.5 \mathrm{dpi}$ and at $7.5 \mathrm{dpi}$ ), led to significant retardation in the growth of all the tumor tissues except that of SW620: no discernable change was observed. The other treatments showed various degrees of anti-tumor activity depending on the tumor cell type except SW620, evidently better than the PBS control or Salmonella alone. We then measured the survival of those tumor-bearing mice treated with the same set of Salmonella (Figure 4B). The results showed that survival was dependent on retardation of tumor growth by Salmonellae carrying or expressing TGF $\alpha$ PE38. Taken together, the data show that TGF $\alpha$-PE38 released from intra-tumoral Salmonellae by the phage lysis system or by the secretion signal effectively retards tumor growth and improves survival.

\section{DISCUSSION}

There are some elements that prevent immunotoxins, particularly TGF $\alpha-\mathrm{PE} 38$, from treating EGFR-expressing tumors successfully. Among these, immunogenicity associated with PE38 derived from Pseudomonas has been virtually eliminated by introducing mutations [47]. However, in all preclinical trials the TGF $\alpha-P E 38$ protein was injected by continuous infusion, mainly due to its short half-life as well as hepatotoxicity [7, 8]. Here, however, we observed a significant effect against EGFR-expressing solid tumors when TGF $\alpha$-PE38 was expressed and released by intra-tumoral Salmonellae (Figure 4). Previously, we compared the distribution of L-asparaginase, an antitumor protein used to treat acute lymphoblastic leukemia, between that expressed and secreted by tumor-targeted Salmonellae and that after intravenous injection [36]. In the latter case, a considerable amount of protein was detected in serum, but little in tumor tissue. By contrast, when mice were treated with Salmonella expressing L-asparaginase, the protein was detected exclusively in tumor tissue, with the amount increasing up to 48 hours after induction. It was suggested that tumor tissue provides an immunoprivileged environment, indeed a sanctuary, for intratumoral bacteria, which can then proliferate to yield up to $10^{9} \mathrm{CFU} \mathrm{g}^{-1}$ tissue $[46,48]$. In addition, we speculate that the tumor tissue provides an environment in which protein drugs produced by intra-tumoral Salmonellae are protected from proteolytic degradation via host systems, thereby prolonging their efficacy. Thus, it should be possible to use other immunotoxins to treat various solid tumors using Salmonellae as a vehicle. It is certain that efficacy of immunotoxin would be greatly augmented when it is delivered by tumor-seeking bacteria.

Here, we used a signal sequence (Psp) to release TGF $\alpha$-PE38 with the aim of achieving greater anti-tumor effects than those obtained with a phage lysis system: in this case, simultaneous induction of both TGF $\alpha$-PE38 and the phage lysis gene by a single inducible $\operatorname{araBAD}$ promoter would reduce the anti-tumor effect because the number of intra-tumoral Salmonellae decreased after each round of induction. Indeed, on $16 \mathrm{dpi}$, after two rounds of induction, only a small numbers of Salmonellae were detectable in the tumor tissue $\left(\sim 20 \mathrm{CFU} / \mathrm{g}^{-1}\right)$, while significant numbers were maintained in the absence of induction $\left(\sim 10^{3} \mathrm{CFU} / \mathrm{g}^{-1}\right)$ (Supplementary Figure 2$)$. Antitumor effect using TGF $\alpha$-PE38 secreted through the signal sequence was only about the same as that observed after release via the phage lysis system. This suggests that it is the initial elicitation of a response by anti-tumor agents in the tumor mass, rather than prolonged exposure, that is critical for establishing an anti-tumor effect, particularly when using intra-tumoral Salmonellae as a drug carrier.

\section{MATERIALS AND METHODS}

\section{Bacterial strains and culture conditions}

$\triangle$ ppGppS. typhimurium, SHJ2037 (relA::cat, spoT::kan), has been previously described [32]. The strain carries an additional mutation in the $\operatorname{glm} S$ gene; therefore, it requires $\mathrm{N}$-acetylglucosamine or $\mathrm{D}$-glucosamine for growth if not complemented by a $g \operatorname{lm} S$-containing plasmid [36]. Bacterial cultures were grown in LB broth (Difco Laboratories) containing $1 \% \mathrm{NaCl}$ with vigorous aeration at $37^{\circ} \mathrm{C}$, unless otherwise indicated. For solid support medium, granulated agar (Difco Laboratories) was includedat $1.5 \%$. Ampicillin (and other antibiotics) was purchased from Sigma Chemicals and added at the following concentration where necessary: $50 \mu \mathrm{g} \mathrm{ml}^{-1}$.

\section{Plasmids}

All plasmids used in this study carried a $g \operatorname{lm} S$ gene as the selective determinant of a balanced-lethal host vector system [36]. In addition, a Salmonella lysis system was also introduced into the plasmid, which comprised a gene from the Salmonellae bacteriophage, iEPS5 phage [34], except in the $p S E C-T G F \alpha-P E 38$ plasmid. The DNA fragment of TGF $\alpha$-PE38 or PE38 was PCR-amplified from plasmid pBR898, a generous gift from Dr. I. Pastan $(\mathrm{NIH})$, as a template; this plasmid contains TGF $\alpha-\mathrm{PE} 38$ under control of the T7 promoter [49]. Each fragment was cloned into the MCS of $p L Y S$ using the EcoR1 and Xba1 sites, to yield $p T G F \alpha-P E 38$ or $p P E 38$, respectively. The Salmonella SEC sequence was amplified from 

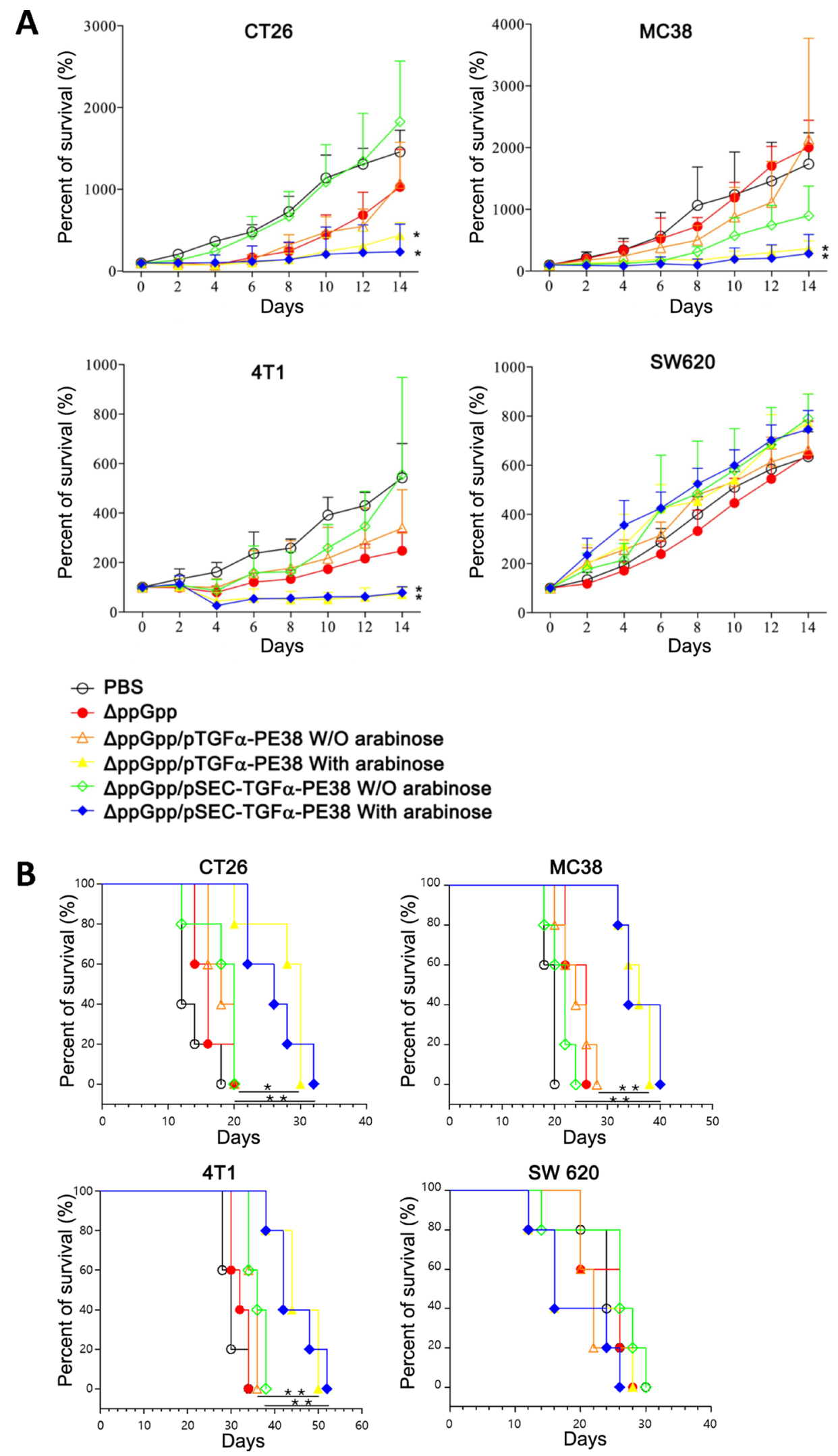

Figure 4: (A) Effects of Salmonella expressing TGF $\alpha$-PE38 on mice implanted with different cancer cell lines ( $n=5 /$ group). BALB/c mice grafted with CT26 and 4T1 tumors, C57BL/6 mice with MC38 tumors, and nude mice with SW620, were analyzed. Percent changes in tumor sizes measured at indicated day relative to that at day $0(100 \%)$ were plotted. (B) Kaplan-Meier survival curves for the tumorbearing mice receiving the treatments described above ( $n=5$ /group). Days in $\mathrm{x}$-axis are after Salmonella injection. $* P<0.05$; $* * P<0.005$. 
Paenibacillus sp. (BCCRC 17757) and then cloned into the plasmid containing no Salmonella lysis system but with a $\operatorname{glm} S$ gene on a pBAD24 backbone ( $p S E C-T G F \alpha$ PE38).

\section{Preparation of anti-tumor proteins expressed by Salmonellae}

Bacterial cells were cultured overnight in LB broth and diluted 1:50 in fresh LB broth prior to incubation at $37^{\circ} \mathrm{C}$. When the $\mathrm{A}_{600}$ reached $0.7, \mathrm{~L}$-arabinose was added at a final concentration of $0.2 \%$. Bacterial cultures were harvested by centrifugation at $3,000 \times \mathrm{g}$ for $15 \mathrm{~min}$. The supernatant fraction was filtered through a $0.45 \mu \mathrm{m}$ filter (SLHV033RS; Merck-Millipore) to remove bacterial cells and then concentrated using Centricon devices (Amicon Ultra $10 \mathrm{~K}$; Millipore).

\section{Cell killing assays}

Cell killing assays were performed using the tumor cell lines, CT26, 4T1, MC38 and SW620. Each cell line was seeded into 24-well plates at a density of $1 \times 10^{5}$ cells per well. After 24 hours, the tumor cells were washed with PBS and placed in serum-free medium containing $500 \mu \mathrm{g}$ of bacterial culture filtrate and induced to express and release TGF $\alpha$-PE38 by addition of L-arabinose. After 24 hours, the number of surviving tumor cells was measured in a 3-(4,5-dimethylthiazol-2-yl)-2,5-diphenyltetrazolium bromide (MTT) assay, as previously described [41].

\section{Western blot analysis}

Total proteins were separated by electrophoresis on $10 \%$ SDS-PAGE gels and then transferred to a nitrocellulose membrane (Bio-Rad). After transfer, the membrane was blocked with 5\% skim milk and probed with a rabbit anti-EGFR antibody (ab2430; Abcam), rabbit anti-Pseudomonas exotoxin A antibody (P2318; SigmaAldrich), or mouse anti $\beta$-actin antibody (sc-47778; Santa Cruz Technology) overnight at $4^{\circ} \mathrm{C}$. After the primary antibodies were washed off with TBS $(140 \mathrm{mM} \mathrm{NaCl}$, $10 \mathrm{mM}$ Tris- $\mathrm{HCl}, \mathrm{pH} 8.0$ ) containing $0.1 \%$ Tween 20 , the membrane was incubated at room temperature for 1 hour with goat anti-rabbit IgG (ab6721; Abcam) or goat anti-mouse IgG (sc-2005; Santa Cruz Technology) conjugated to horseradish peroxidase. Bound proteins were visualized using an ECL kit (Amersham Biosciences).

\section{Culture of tumor cell lines}

CT26 mouse colon carcinoma and 4T-1 mouse breast carcinoma cell lines were grown in high-glucose Dulbecco's Modified Eagle Medium containing 10\% fetal bovine serum and $1 \%$ penicillin-streptomycin. MC38 cells were grown in Minimum Essential Medium, and
SW620 human coloncarcinoma cells were grown in RPMI medium.

\section{Mouse experiments}

Male BALB/c. C57BL/6 mice, and nude mice (5-6weeks old; 16-18g) were purchased from the Samtako Company, Korea. All animal care, experiments, and euthanasia were performed in accordance with protocols approved by the Chonnam National University Animal Research Committee. Tumor-bearing mice were generated by subcutaneously implanting cultured tumor cells $\left(1 \times 10^{6}\right)$ suspended in $50 \mu \mathrm{l}$ of PBS into the right thigh. After about 10-15 days, when tumors reached approximately $100-150 \mathrm{~mm}^{3}$, mice were injected (into tail vein) with $S$. typhimurium carrying various plasmids. Anesthesia prior to imaging was performed using isoflurane (2\%). Anesthesia prior to surgery was performed using a mixture of ketamine $\left(200 \mathrm{mg} \mathrm{kg}^{-1}\right)$ and xylazine $\left(10 \mathrm{mg} \mathrm{kg}^{-1}\right)$.

\section{Counting bacterial cells in tumor tissue}

Each solid tumor was excised from implanted mice and homogenized in $5 \mathrm{ml}$ of PBS containing $0.05 \%$ Triton X-100. The homogenized tissues were diluted in PBS and plated on LB agar plates containing appropriate antibiotics. On the following day, bacterial numbers were counted on plates incubated at $37^{\circ} \mathrm{C}$. The number of infecting bacteria was enumerated as follows: the number of bacteria $\times$ dilution factor $/ g$ of solid tumor tissue.

\section{Statistical analysis}

Two-tailed Student's $t$ tests were used to determine the significance of differences in primary tumor growth between the control and treated groups. For the MTT assay, statistical significance was determined using the Mann-Whitney $U$ test. Survival analysis was performed using Kaplan-Meier curves and the log-rank test. $P<0.05$ was considered significant for all analyses. All data are expressed as the mean $\pm \mathrm{SD}$.

\section{ACKNOWLEDGMENTS}

We thank Dr. Ira Pastan (NIH. USA) for providing the genetic material (TGF $\alpha$-PE38) and helpful discussion.

\section{CONFLICTS OF INTEREST}

The Authors do not have any conflicts of interest.

\section{GRANT SUPPORT}

This work has been supported by a grant a National Research Foundation of Korea grant funded by the 
Korea government (NRF-2014R1A2A1A10051664). J.J.M was supported by the Pioneer Research Center Program (2015M3C1A3056410) and the Bio \& Medical Technology Development Program of the National Research Foundation (NRF) funded by the Ministry of Science, ICT \& Future Planning (NRF2014M3A9B5073747). J.H.J was supported by Basic Science Research Program (NRF-2014R1A1A2006327) and K.S.K by Basic Science Research Program (NRF2014R1A1A2004637). K.C.K., J.J.S., and J.H.C were supported by a basic research grant from KRIBB.

\section{REFERENCES}

1. Siegall CB, FitzGerald DJ, Pastan I. Selective killing of tumor cells using EGF or TGF alpha-Pseudomonas exotoxin chimeric molecules. Semin Cancer Biol. 1990; $1: 345-350$.

2. Alewine C, Hassan R, Pastan I. Advances in anticancer immunotoxin therapy. Oncologist. 2015; 20:176-185.

3. Grandis JR, Tweardy DJ. Elevated levels of transforming growth factor alpha and epidermal growth factor receptor messenger RNA are early markers of carcinogenesis in head and neck cancer. Cancer Res. 1993; 53:3579-3584.

4. Phillips PC, Levow C, Catterall M, Colvin OM, Pastan I, Brem $\mathrm{H}$. Transforming growth factor-alpha-Pseudomonas exotoxin fusion protein (TGF-alpha-PE38) treatment of subcutaneous and intracranial human glioma and medulloblastoma xenografts in athymic mice. Cancer Res. 1994; 54:1008-1015.

5. Rubin Grandis J, Chakraborty A, Melhem MF, Zeng Q, Tweardy DJ. Inhibition of epidermal growth factor receptor gene expression and function decreases proliferation of head and neck squamous carcinoma but not normal mucosal epithelial cells. Oncogene. 1997; 15:409-416.

6. Weldon JE, Pastan I. A guide to taming a toxin--recombinant immunotoxins constructed from Pseudomonas exotoxin A for the treatment of cancer. FEBS J. 2011; 278:4683-4700.

7. Wright SE, Rewers-Felkins KA, Quinlin I, Chowdhury NI, Ahmed J, Eldridge PW, Srivastava SK, Pastan I. TGFalphaPE38 enhances cytotoxic T-lymphocyte killing of breast cancer cells. Oncol Lett. 2014; 7:2113-2117.

8. Pai LH, Batra JK, FitzGerald DJ, Willingham MC, Pastan I. Anti-tumor activities of immunotoxins made of monoclonal antibody B3 and various forms of Pseudomonas exotoxin. Proc Natl Acad Sci U S A. 1991; 88:3358-3362.

9. Ochiai H, Archer GE, Herndon JE 2nd, Kuan CT, Mitchell DA, Bigner DD, Pastan IH, Sampson JH. EGFRvIII-targeted immunotoxin induces antitumor immunity that is inhibited in the absence of CD4+ and CD8+ T cells. Cancer Immunol Immunother. 2008; 57:115-121.

10. Pawelek JM, Low KB, Bermudes D. Tumor-targeted Salmonella as a novel anticancer vector. Cancer Res. 1997; $57: 4537-4544$
11. Agrawal N, Bettegowda C, Cheong I, Geschwind JF, Drake CG, Hipkiss EL, Tatsumi M, Dang LH, Diaz LA Jr, Pomper M, Abusedera M, Wahl RL, Kinzler KW, et al. Bacteriolytic therapy can generate a potent immune response against experimental tumors. Proc Natl Acad Sci USA. 2004; 101:15172-15177.

12. Kimura NT, Taniguchi S, Aoki K, Baba T. Selective localization and growth of Bifidobacterium bifidum in mouse tumors following intravenous administration. Cancer Res. 1980; 40:2061-2068.

13. Yu YA, Shabahang S, Timiryasova TM, Zhang Q, Beltz R, Gentschev I, Goebel W, Szalay AA. Visualization of tumors and metastases in live animals with bacteria and vaccinia virus encoding light-emitting proteins. Nat Biotechnol. 2004; 22:313-320.

14. Zhao M, Yang M, Li XM, Jiang P, Baranov E, Li S, Xu M, Penman S, Hoffman RM. Tumor-targeting bacterial therapy with amino acid auxotrophs of GFP-expressing Salmonella typhimurium. Proc Natl Acad Sci USA. 2005; 102:755-760.

15. Taniguchi S, Fujimori M, Sasaki T, Tsutsui H, Shimatani Y, Seki K, Amano J. Targeting solid tumors with nonpathogenic obligate anaerobic bacteria. Cancer Sci. 2010; 101:1925-32.

16. Thamm DH, Kurzman ID, King I, Li Z, Sznol M, Dubielzig RR, Vail DM, MacEwen EG. Systemic administration of an attenuated, tumor-targeting Salmonella typhimurium to dogs with spontaneous neoplasia: phase I evaluation. Clin Cancer Res. 2005; 11:4827-4834.

17. Toso JF, Gill VJ, Hwu P, Marincola FM, Restifo NP, Schwartzentruber DJ, Sherry RM, Topalian SL, Yang JC, Stock F, Freezer LJ, Morton KE, Seipp C, et al. Phase I study of the intravenous administration of attenuated Salmonella typhimurium to patients with metastatic melanoma. J Clin Oncol. 2002; 20:142-152.

18. Roberts NJ, Zhang L, Janku F, Collins A, Bai RY, Staedtke V, Rusk AW, Tung D, Miller M, Roix J, Khanna KV, Murthy R, Benjamin RS, et al. Intratumoral injection of Clostridium novyi-NT spores induces antitumor responses. Sci Transl Med. 2014; 6:249ra111.

19. Weibel S, Stritzker J, Eck M, Goebel W, Szalay AA. Colonization of experimental murine breast tumours by Escherichia coli K-12 significantly alters the tumour microenvironment. Cell Microbiol. 2008; 10:1235-1248.

20. Nguyen VH, Kim HS, Ha JM, Hong Y, Choy HE, Min JJ. Genetically engineered Salmonella typhimurium as an imageable therapeutic probe for cancer. Cancer Res. 2010; 70:18-23.

21. Ryan RM, Green J, Williams PJ, Tazzyman S, Hunt S, Harmey JH, Kehoe SC, Lewis CE. Bacterial delivery of a novel cytolysin to hypoxic areas of solid tumors. Gene Ther. 2009; 16:329-339.

22. Jiang SN, Phan TX, Nam TK, Nguyen VH, Kim HS, Bom HS, Choy HE, Hong Y, Min JJ. Inhibition of tumor growth and metastasis by a combination of Escherichia coli-mediated cytolytic therapy and radiotherapy. Mol Ther. 2010; 18:635-642. 
23. Hayashi K, Zhao M, Yamauchi K, Yamamoto N, Tsuchiya H, Tomita K, Hoffman RM. Cancer metastasis directly eradicated by targeted therapy with a modified Salmonella typhimurium. J Cell Biochem. 2009; 106:992-998.

24. Nagakura $C$, Hayashi $K$, Zhao $M$, Yamauchi $K$, Yamamoto N, Tsuchiya $\mathrm{H}$, Tomita $\mathrm{K}$, Bouvet $\mathrm{M}$, Hoffman RM. Efficacy of a genetically-modified Salmonella typhimurium in an orthotopic human pancreatic cancer in nude mice. Anticancer Res. 2009; 29:1873-1878.

25. Yam C, Zhao M, Hayashi $\mathrm{K}$, Ma $\mathrm{H}$, Kishimoto $\mathrm{H}$, McElroy M, Bouvet M, Hoffman RM. Monotherapy with a tumor-targeting mutant of S. typhimurium inhibits liver metastasis in a mouse model of pancreatic cancer. J Surg Res. 2010; 164:248-255.

26. Zhao M, Geller J, Ma H, Yang M, Penman S, Hoffman RM. Monotherapy with a tumor-targeting mutant of Salmonella typhimurium cures orthotopic metastatic mouse models of human prostate cancer. Proc Natl Acad Sci USA. 2007; 104:10170-10174.

27. Zhao M, Yang M, Ma H, Li X, Tan X, Li S, Yang Z, Hoffman RM. Targeted therapy with a Salmonella typhimurium leucine-arginine auxotroph cures orthotopic human breast tumors in nude mice. Cancer Res. 2006; 66:7647-7652.

28. Yano S, Takehara K, Zhao M, Tan Y, Han Q, Li S, Bouvet M, Fujiwara T, Hoffman RM. Tumor-specific cellcycle decoy by Salmonella typhimurium A1-R combined with tumor-selective cell-cycle trap by methioninase overcome tumor intrinsic chemoresistance as visualized by FUCCI imaging. Cell Cycle. 2016; 15:1715-1723.

29. Hiroshima Y, Zhao M, Zhang Y, Zhang N, Maawy A, Murakami T, Mii S, Uehara F, Yamamoto M, Miwa S, Yano S, Momiyama M, Mori R, et al. Tumor-Targeting Salmonella typhimurium A1-R Arrests a Chemo-Resistant Patient Soft-Tissue Sarcoma in Nude Mice. PLoS One. 2015; 10:e134324.

30. Yano S, Zhang Y, Zhao M, Hiroshima Y, Miwa S, Uehara F, Kishimoto H, Tazawa H, Bouvet M, Fujiwara T, Hoffman RM. Tumor-targeting Salmonella typhimurium A1-R decoys quiescent cancer cells to cycle as visualized by FUCCI imaging and become sensitive to chemotherapy. Cell Cycle. 2014; 13:3958-3963.

31. Song M, Kim HJ, Ryu S, Yoon H, Yun J, Choy HE. ppGppmediated stationary phase induction of the genes encoded by horizontally acquired pathogenicity islands and cob/ pdu locus in Salmonella enterica serovar Typhimurium. J Microbiol. 2010; 48:89-95.

32. Song M, Kim HJ, Kim EY, Shin M, Lee HC, Hong Y, Rhee JH, Yoon H, Ryu S, Lim S, Choy HE. ppGppdependent stationary phase induction of genes on Salmonella pathogenicity island 1. J Biol Chem. 2004; 279:34183-34190.

33. Kim JE, Phan TX, Nguyen VH, Dinh-Vu HV, Zheng JH, Yun M, Park SG, Hong Y, Choy HE, Szardenings M,
Hwang W, Park JA, Park S, et al. Salmonella typhimurium Suppresses Tumor Growth via the Pro-Inflammatory Cytokine Interleukin-1beta. Theranostics. 2015; 5:1328-1342.

34. Jeong JH, Kim K, Lim D, Jeong K, Hong Y, Nguyen VH, Kim TH, Ryu S, Lim JA, Kim JI, Kim GJ, Kim SC, Min JJ, et al. Anti-tumoral effect of the mitochondrial target domain of Noxa delivered by an engineered Salmonella typhimurium. PLoS One. 2014; 9:e80050.

35. Min JJ, Nguyen VH, Kim HJ, Hong Y, Choy HE. Quantitative bioluminescence imaging of tumor-targeting bacteria in living animals. Nat Protoc. 2008; 3:629-636.

36. Kim K, Jeong JH, Lim D, Hong Y, Yun M, Min JJ, Kwak SJ, Choy HE. A novel balanced-lethal host-vector system based on glmS. PLoS One. 2013; 8:e60511.

37. Choi JH, Lee SY. Secretory and extracellular production of recombinant proteins using Escherichia coli. Appl Microbiol Biotechnol. 2004; 64:625-635.

38. Lei SP, Lin HC, Wang SS, Callaway J, Wilcox G. Characterization of the Erwinia carotovora pelB gene and its product pectate lyase. J Bacteriol. 1987; 169:4379-4383.

39. Ko KC, Lee JH, Han Y, Choi JH, Song JJ. A novel multifunctional cellulolytic enzyme screened from metagenomic resources representing ruminal bacteria. Biochem Biophys Res Commun. 2013; 441:567-572.

40. Na HS, Kim HJ, Lee HC, Hong Y, Rhee JH, Choy HE. Immune response induced by Salmonella typhimurium defective in ppGpp synthesis. Vaccine. 2006; 24:2027-2034.

41. Thomas SM, Grandis JR. Pharmacokinetic and pharmacodynamic properties of EGFR inhibitors under clinical investigation. Cancer Treat Rev. 2004; 30:255-268.

42. Turker NS, Heidari P, Kucherlapati R, Kucherlapati M, Mahmood U. An EGFR targeted PET imaging probe for the detection of colonic adenocarcinomas in the setting of colitis. Theranostics. 2014; 4:893-903.

43. Dykxhoorn DM, Wu Y, Xie H, Yu F, Lal A, Petrocca F, Martinvalet D, Song E, Lim B, Lieberman J. miR-200 enhances mouse breast cancer cell colonization to form distant metastases. PLoS One. 2009; 4:e7181.

44. Balin-Gauthier D, Delord JP, Rochaix P, Mallard V, Thomas F, Hennebelle I, Bugat R, Canal P, Allal C. In vivo and in vitro antitumor activity of oxaliplatin in combination with cetuximab in human colorectal tumor cell lines expressing different level of EGFR. Cancer Chemother Pharmacol. 2006; 57:709-718.

45. Dua R, Zhang J, Nhonthachit P, Penuel E, Petropoulos C, Parry G. EGFR over-expression and activation in high HER2, ER negative breast cancer cell line induces trastuzumab resistance. Breast Cancer Res Treat. 2010; 122:685-697.

46. Min JJ, Kim HJ, Park JH, Moon S, Jeong JH, Hong YJ, Cho KO, Nam JH, Kim N, Park YK, Bom HS, Rhee JH, Choy HE. Noninvasive real-time imaging of tumors and metastases using tumor-targeting light-emitting Escherichia coli. Mol Imaging Biol. 2008; 10:54-61. 
47. Pastan I, Hassan R, FitzGerald DJ, Kreitman RJ. Immunotoxin treatment of cancer. Annu Rev Med. 2007; 58:221-237.

48. Forbes NS. Engineering the perfect (bacterial) cancer therapy. Nat Rev Cancer. 2010; 10:785-794.
49. Theuer CP, Kreitman RJ, FitzGerald DJ, Pastan I. Immunotoxins made with a recombinant form of Pseudomonas exotoxin A that do not require proteolysis for activity. Cancer Res. 1993; 53:340-347. 